\title{
The sub-fossil red coral of Sciacca (Sicily Channel, Mediterranean Sea): colony size and age estimates
}

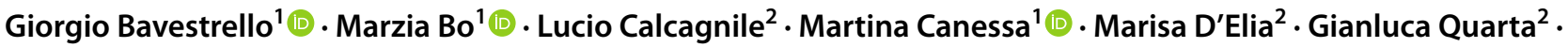 \\ Federico Spagnoli ${ }^{3}$ (D) $\cdot$ Riccardo Cattaneo-Vietti $^{1}$ (1)
}

Received: 16 June 2020 / Accepted: 29 December 2020 / Published online: 7 February 2021

(c) The Author(s) 2021

\begin{abstract}
The Mediterranean red coral, Corallium rubrum (L.), has been a valuable economic resource for more than 2000 years. The Sicily Channel and surrounding areas are one of the most famous red coral fishing grounds of the whole region, hosting the deepest ever found living colonies and large sub-fossil red coral deposits; the so-called Sciacca banks are a unique location in the whole Mediterranean Sea. In this paper, a morphometric description of this sub-fossil population is presented for the first time from studies of colonies in the collection of several coral factories from Torre del Greco (Naples), with radiocarbon age estimations and growth rate evaluations. From the results of this study, after several thousand years Sciacca red coral colonies maintained the organic matrix structure with evident annual discontinuities, allowing estimations of the annual growth rate (about $0.3 \mathrm{~mm} /$ year) and the average population age (about 33.5 years). These resulting data are similar to the values determined for deep-dwelling living red coral populations. The radiocarbon dating evidenced a range of ages, from 8300 to 40 years before $1950 \mathrm{CE}$, mostly falling between 2700 and $3900 \mathrm{YBP}$, suggesting that colonies accumulated over a wide span of time. In view of the tectonically active nature of the area, several catastrophic events affected these ancient populations, maintaining them in a persistent state of early-stage, structurally similar to the those in current over-exploited areas.
\end{abstract}

Keywords Sub-fossil red coral $\cdot$ Morphometric analysis $\cdot$ Growth rate $\cdot$ Radiocarbon aging $\cdot$ Sicily channel

\section{Introduction}

The precious red coral (Corallium rubrum L.) is a longliving, slow-growing colonial octocoral that represents one of the most significant marine species of the Mediterranean Sea, often taking on important anthropological meanings. This species produces an easily workable axial skeleton (Vielzeuf et al. 2008), composed of high-magnesiumcalcite, which has been a valuable economic resource for

Martina Canessa

marti.canessa@gmail.com

1 DISTAV, Department of Science of Earth, Environment and Life, University of Genoa, Corso Europa 26, 16100 Genoa, Italy

2 CEDAD (Centre for Applied Physics, Dating and Diagnostics), Department of Mathematics and Physics "Ennio De Giorgi", University of Salento, Salento, Italy

3 CNR IRBIM of Ancona (Istituto per le Risorse Biologiche e le Biotecnologie Marine), Largo Fiera della Pesca 2, 60125 Ancona, Italy
Mediterranean fishermen for more than 2000 years (Tsounis et al. 2010; Cattaneo-Vietti and Bavestrello 2010; Cattaneo-Vietti et al. 2016). Density and colony morphology may vary from place to place, according to depth, current exposure and human pressures. The coastal coral populations occurring down to $40-50 \mathrm{~m}$ depth are characterised by high density (up to 1000 colonies $/ \mathrm{m}^{2}$ ) and small colony size (less than $5 \mathrm{~cm}$ in height), whereas the deeper ones, extending down to $200 \mathrm{~m}$ water depth and more, form small aggregates, mainly in high-current areas, with low density, high colony size and extensive branching patterns (Rossi et al. 2008; Tsounis et al. 2006; Cau et al. 2013, 2016; Mallo et al. 2019).

Our knowledge about the demographic features of the shallow-water populations, in terms of density and colony morphology, has increased considerably in recent years, even if it is not always easy to understand whether the actual structures are natural or adulterated, as a result of overfishing which these populations have been subject to over time (Tsounis et al. 2010; Bramanti et al. 2014). On the contrary, the deeper ones (the main target of harvesting today) 
remain poorly known due to their remoteness and constitute an endangered resource (Otero et al. 2016), even though fishing pressures have progressively decreased in the last decade (Cattaneo-Vietti et al. 2016).

The Sicily Channel and surrounding areas have been and remain one of the most famous red coral fishing grounds in the whole Mediterranean (Cattaneo-Vietti et al. 2016, 2017), hosting the deepest ever found living colonies, down to depths of $1016 \mathrm{~m}$ around the Maltese Islands (Costantini et al. 2010; Taviani et al. 2010; Knittweis et al. 2016).

The Sicily Channel also hosts large sub-fossil red coral deposits discovered between 1875 and 1880 off Sciacca, a small town along the southern coast of Sicily, at depths ranging from 150 to $200 \mathrm{~m}$ (Rajola 2012). Although red coral fossil colonies, in some cases maintaining traces of colour, are known from Miocene to Pleistocene deposits in several Italian sites (Neviani 1935; Vertino et al. 2010), the only extensive sub-fossil deposits found in the Mediterranean basin are those of Sciacca, reaching back to 9,000 YBP (Di Geronimo et al. 1993; Lodolo et al. 2017). The formation of the Sciacca red coral banks is an extraordinary event in red coral bio-history that has taken place over several millennia at this site (Cattaneo-Vietti and Bavestrello 2010). Between 1875 and 1914, 18,000 tons of raw material, scattered across the seafloor, were harvested, and the banks entirely depleted (Liverino 1998; Rajola 2012; Cattaneo-Vietti et al. 2016). Not all of the raw material collected in those years has been worked on and sold. Still today, several factories from Torre del Greco (Naples) retain various untouched quantities. Thanks to the courtesy of three historic red coral factories (Ascione, De Simone and Rajola), famous in working and trading red coral jewellery all around the world, we have had the opportunity to study several colony fragments, collected over a 40-year period between the end of the nineteenth century and the beginning of the twentieth century. Thanks to these samples, it was possible to define for the first time the colony size, age and growth rate, enabling comparisons with modern deep-water populations present in the western Mediterranean Sea and Atlantic Ocean.

\section{Materials and methods}

\section{Study area}

The Sciacca red coral deposits appear to be a unique formation in the whole Mediterranean Sea. The first bank, discovered in May 1875, was approximately $16 \mathrm{NM}$ off the coast $\left(37^{\circ} 20^{\prime} 3^{\prime \prime} \mathrm{N} ; 12^{\circ} 48^{\prime} 7^{\prime \prime} \mathrm{E}\right)$ and $2.5 \mathrm{NM}$ long and $2 \mathrm{NM}$ wide (Mazzarelli 1915). Two other banks were found in the following years, on August 1878 and January 1880, at $37^{\circ} 14^{\prime} 7^{\prime \prime} \mathrm{N} ; 12^{\circ} 43^{\prime} 3^{\prime \prime} \mathrm{E}$ (24 NM off Sciacca) and $37^{\circ} 5^{\prime} \mathrm{N}$; $12^{\circ} 36^{\prime} 3^{\prime \prime}$ E (33 NM off Sciacca), respectively (Liverino
1998; Rajola 2012) (Fig. 1). These deposits were located within a wide submarine valley, called "the coral valley", in an area which hosts, among other submarine rocky edifices, the Graham Bank, a broad and relatively shallow relief, which corresponds to the location of the ephemeral so-called Ferdinandea Island, which appeared in 1831 as a result of an explosive eruption and rapidly disappeared after a few months. The red coral colonies, living on the rocky flanks of the valley, when died, rolled down and accumulated onto the seafloor, creating the red coral deposits, intermingled with volcanic and biogenic debris (Lodolo et al. 2017).

\section{Sample analysis}

\section{Morphometric features}

Thanks to the kindness of several "corallari" factories of Torre del Greco (Naples), we have had the opportunity to study samples coming from the abundant deposits discovered in the late nineteenth century in the Sicily Channel. No precise information about the exact location or year of collection is available. The raw material is mainly composed of small fragments, generally less than $5 \mathrm{~cm}$ long, with shades of red/orange. Only a few almost complete colonies were present in the samples from the De Simone collection.

For the morphometric analysis, only colonies' bases were selected, recognisable by the portion of substrate still attached, for a total of 125 fragments. For all specimens, the diameter of each base was measured with a calliper. Thanks to the equations proposed by Mallo et al. (2019), which relate the basal diameter to height and weight of a red coral colony, the average height and weight of the sub-fossil population were tentatively estimated, although the equations were based on data from shallow-water populations (<60 m depth).

\section{Radiometric dating}

The age of ten specimens was obtained by radiocarbon dating using an Accelerator Mass Spectrometry (AMS) at the Center of Dating and Diagnostics (CEDAD) of the University of Salento (Calcagnile et al. 2005, 2019). Samples were converted to carbon dioxide by acid hydrolysis $\left(\mathrm{H}_{3} \mathrm{PO}_{4}\right)$, and the extracted $\mathrm{CO}_{2}$ was converted to graphite after cryogenic purification (D'Elia et al. 2004). Conventional radiocarbon ages were then calculated from the ${ }^{14} \mathrm{C} /{ }^{12} \mathrm{C}$ isotopic ratios measured with the AMS system after correcting for isotopic fractionation, chemical processing and machine background. Conventional radiocarbon ages were then calibrated in calendar years, expressed as years before $1950 \mathrm{CE}$, using the MARINE13 curve (Reimer et al. 2013) and a $\Delta R=58 \pm 15$, as the average value for the Mediterranean Sea (Reimer and McCormac 2002). 


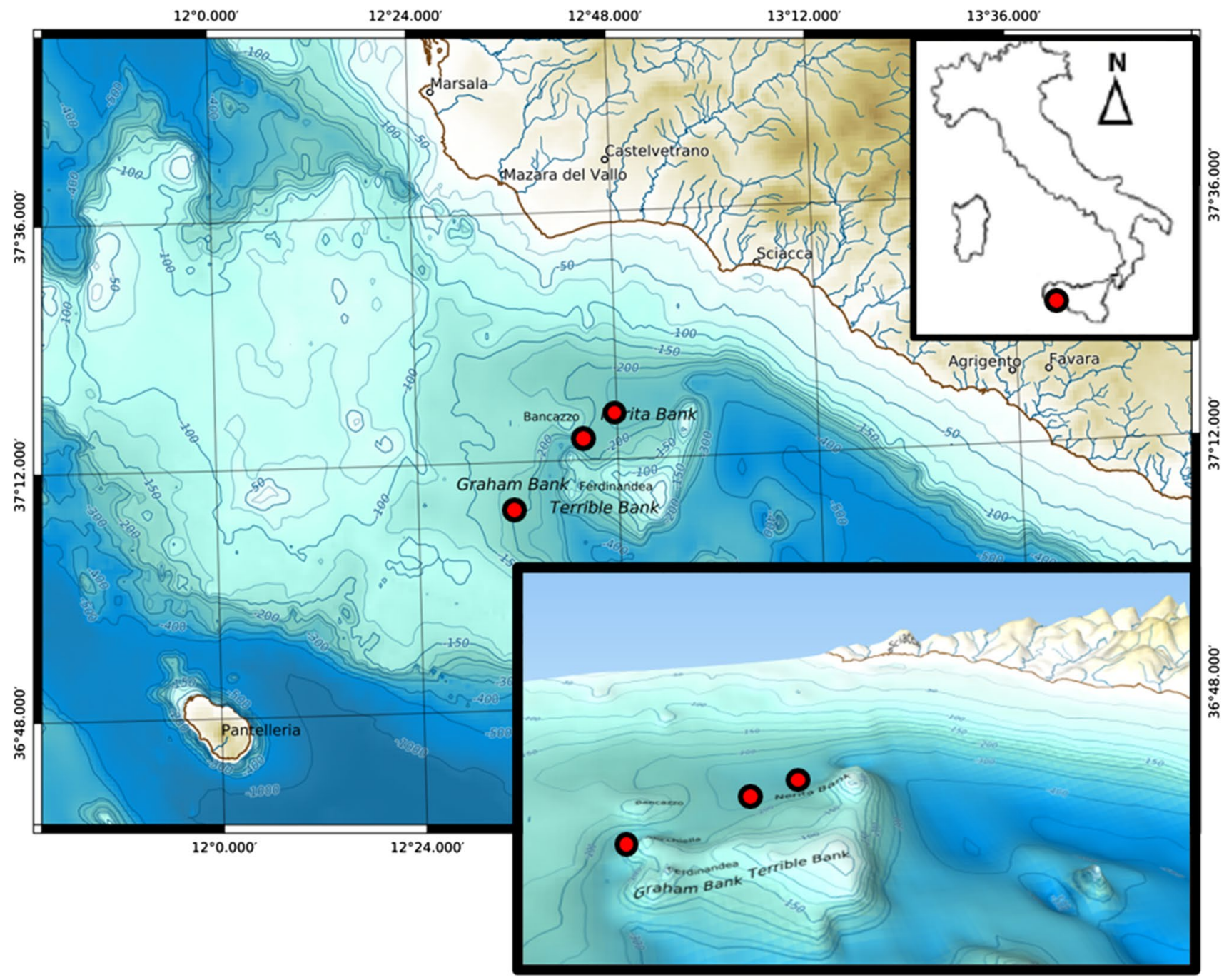

Fig. 1 Location of the three Sciacca banks in the Sicily Channel. The 3D enlargement shows the so-called "coral valley" at the base of the NW slope of the shoals that remain after the sudden disappearance of Ferdinandea Island (1831)

\section{Growth rate estimation}

The growth rate of ten colonies was estimated from thinsections according to the organic matrix staining method (Marschal et al. 2004). Two scleraxis sections, $20 \mu \mathrm{m}$ thick, per specimen, were decalcified with $2 \%$ acetic acid solution overnight and stained with Toluidine blue at $0.05 \%$ for $60 \mathrm{~s}$. The stained sections were photographed under a stereomicroscope. Each image was calibrated according to the exact magnification and processed by the graphic software ImageJ (Rasband 1997). Growth rates were estimated as the average number of growth rings recorded along four radial transects, from the centre to the edge, avoiding holes made by boring sponges as well as the irregular morphology of some colonies that masked annual growth rings (Priori et al. 2013). The age of the colonies was calculated by adding 4 to the number of average sclerochronological rings counted, according to the method proposed by Marschal et al. (2004). The annual growth rate was calculated dividing the average basal diameter by the average number of rings.

\section{Results}

The available sub-fossil red coral colonies from the Sciacca banks were broken in such a way that, generally, it was not possible to determine the morphology of the whole colony (Fig. 2a). The broken nature of the branches results in differences in their preservation: in some cases, their surfaces are characterised by the typical longitudinal furrows and hollows which are generally present in the living coral scleraxis (Fig. 3a, b). In others, the surfaces are completely smooth, probably due to abrasion or dissolution (Fig. 3c). The colour varies from orange to salmon pink, in some cases with 

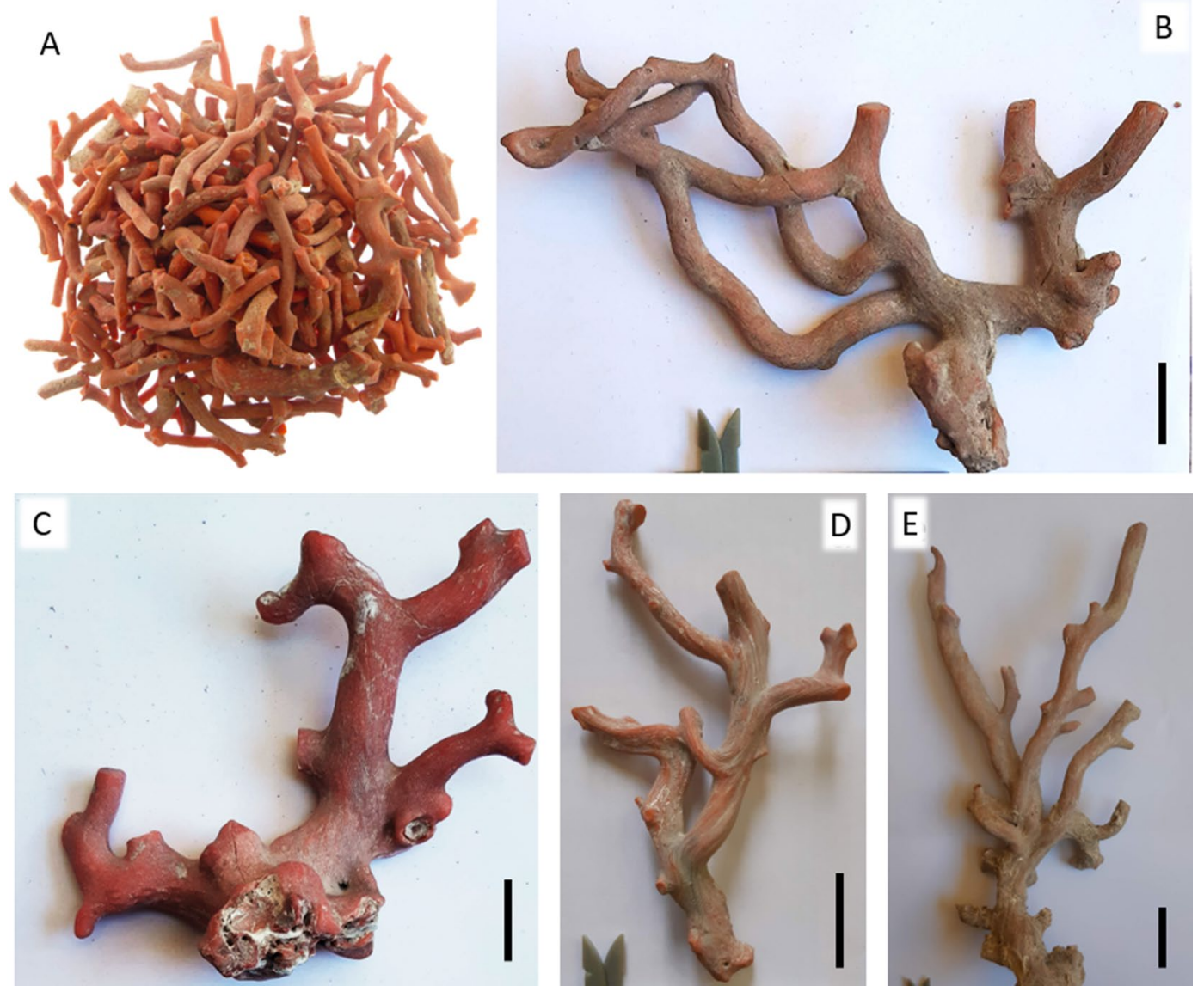

Fig. 2 Coral specimens from the Sciacca banks. Raw materials (a) selected colonies in different states of integrity (b-e). Scale bars, $1 \mathrm{~cm}$

yellow spots which grade towards a darker or even black colour, as a result of bacterial oxidation. Serpulids, bryozoans and carbonate crusts are commonly present on the fragments (Fig. 3d, e). Some bases and branches are bored, likely by polychaetes (Fig. 3f, g) or sponges (Fig. 3h). The selected bases maintain their morphology and, in several cases, fragments of the original substrate (Fig. 3i-k).

The average basal diameter of all the examined specimens is $9.85 \pm 0.44 \mathrm{~mm}$. Some colonies are almost intact (Fig. 2b-e). The largest one has a basal diameter of $18.9 \mathrm{~mm}$, a height of 15.8 and a weight of $28.5 \mathrm{~g}$, with 21 apices. The colony shape is variable, and numerous anastomoses among secondary branches are present in several colony fragments (Fig. 2b). The size-frequency distribution of the basal diameters shows a unimodal trend, in the class at $6-8 \mathrm{~mm}$ (Fig. 4a). On the basis of the recorded basal diameters and applying the equations proposed by Mallo et al. (2019), the estimated average height was of $8 \pm 0.39 \mathrm{~cm}$ and the weight resulted in $12.3 \pm 0.8 \mathrm{~g}$ (Table 1 ).

The age determinations of the ten specimens indicated that the studied samples covered a large time interval, ranging from about 8300 to 40 years before $1950 \mathrm{CE}$ with two thirds of the specimens falling between 2700 and 3900
YBP (Table 2). The same specimens, with a basal diameter between 7 and $13 \mathrm{~mm}$, were used to test for the efficiency of the staining method to determine the presence of the organic matrix in the scleraxis of the sub-fossil specimens. In section, the coral colonies show a very dense organisation of the calcite crystals; the deep orange colour is homogeneous but the main annual rings are visible (Fig. 5a). When the sections are demineralised and stained all the annual rings are evident and easily distinguishable (Fig. 5b, c). By counting these discontinuity markers, the average age of the studied colonies resulted in $33.5 \pm 0.8$ years with a maximum of 43 years. Consequently, the estimated growth rate (average basal diameter/colony age) was, on average, $0.3 \pm 0.01 \mathrm{~mm} /$ year (Table 1) and this appears to have been fairly stable throughout the considered millennia.

\section{Discussion}

The formation of the Sciacca sub-fossil red coral banks represents a unique and perhaps unrepeatable phenomenon, whose origin remains unresolved, although likely associated with the volcanic and seismic activities that characterise 

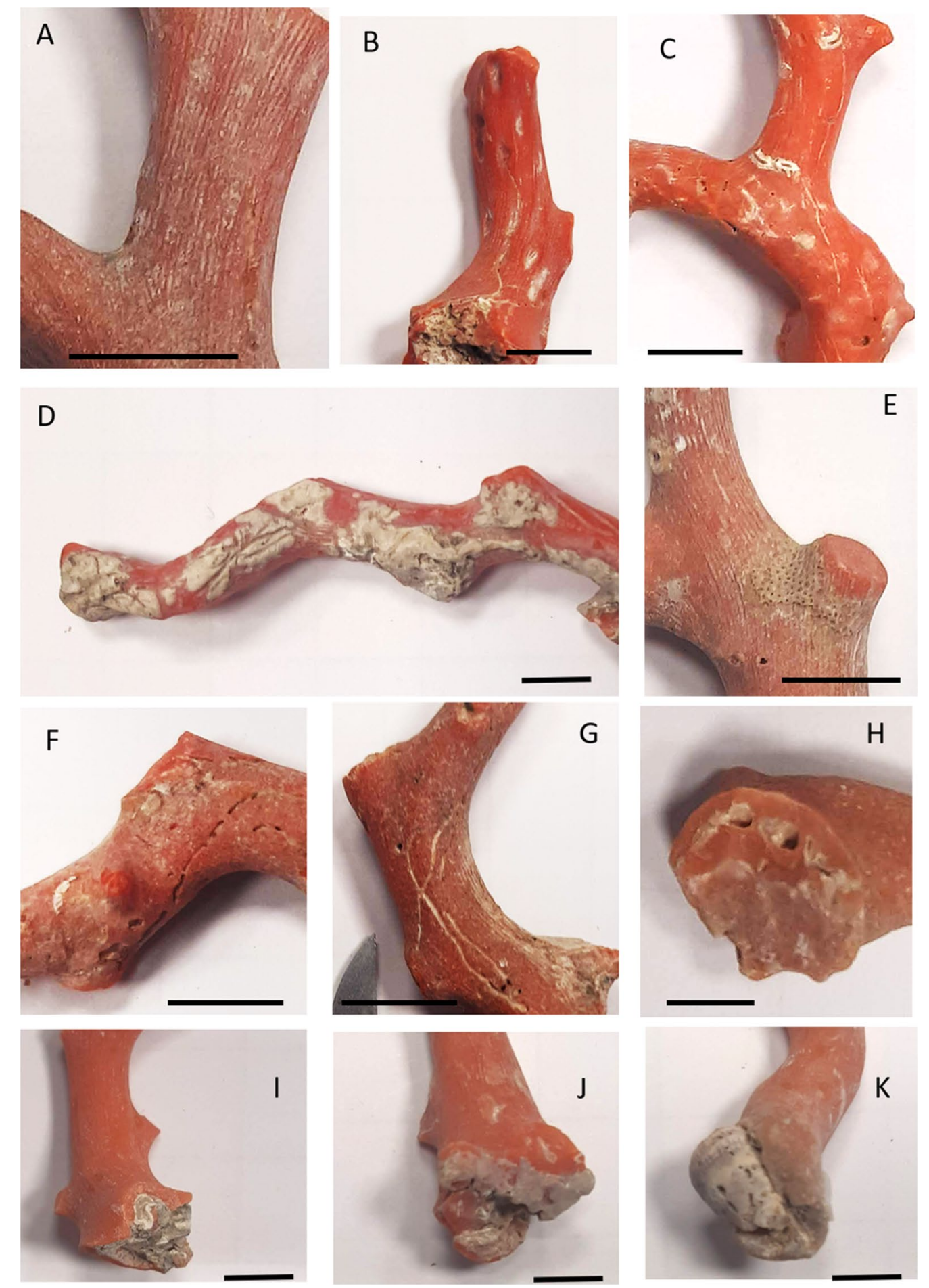

Fig. 3 Broken branches in different status of preservation. Specimens with the typical longitudinal furrows (a) and hollows (b). A completely smooth branch $(\mathbf{c})$. Serpulids $(\mathbf{d})$, bryozoans (e) present on the

the Sicily Channel (Coltelli et al. 2016; Lodolo et al. 2017; Fedorik et al. 2018). The results of this study have provided, for the first time, some morphometric parameters, measured (basal diameter) and estimated (colony height and weight) fragments. Some branches bored by polychaetes (f, g) and sponges (h). Colony bases maintaining their original shape and part of their rocky substrate $(\mathbf{i}-\mathbf{k})$. Scale bars, $0.5 \mathrm{~cm}$

of the sub-fossil coral populations that have followed one another over the millennia at this site and have been harvested over 40 years between the end of the nineteenth century and the beginning of the twentieth century. 

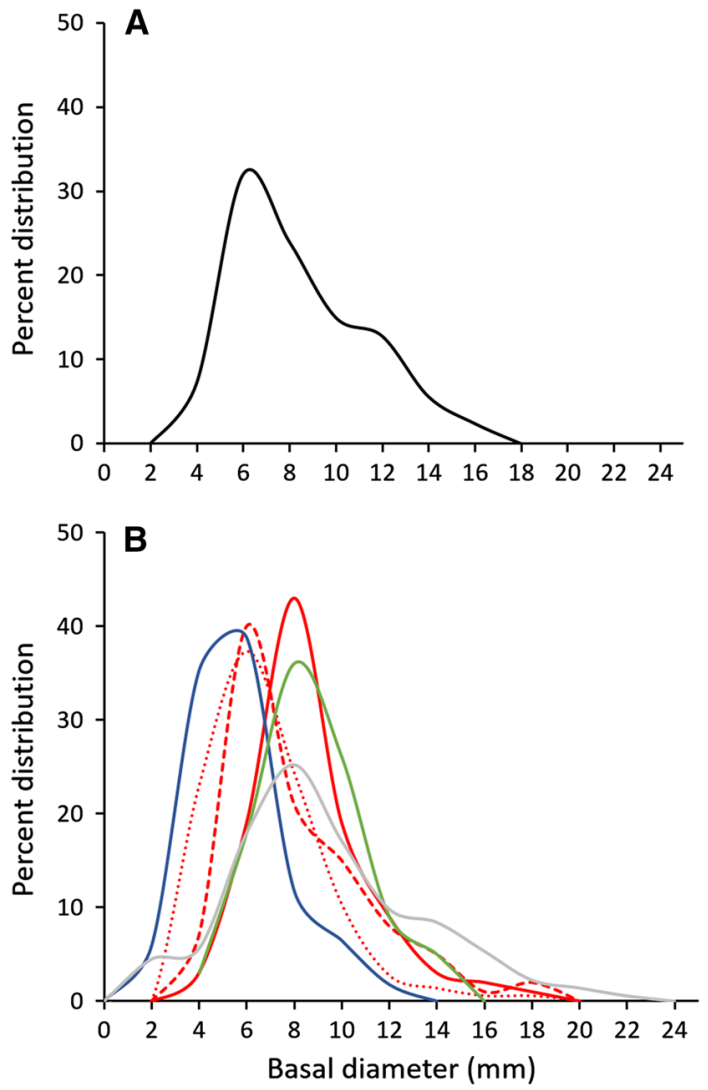

Fig. 4 Size-frequency distribution of the basal diameter in the Sciacca population (a) in comparison (b) to deep ones from other Mediterranean sectors: NW Sardinia (red solid line), SW Sardinia (red dotted line), SE Sardinia (red stacked line), Tuscany Archipelago (blue line), Catalan (green line) and Portuguese coast (grey line). For the references, see Table 1

The size and shape of a red coral colony is strongly affected by a complex set of environmental and biotic variables, such as current flux, light intensity, sedimentation rate and trophic conditions, fecundity, recruitment, spatial competition, presence of boring sponges and, finally, fishing pressure (Bramanti et al. 2014; Tsounis et al. 2006, 2016; Vielmini et al. 2009). Notwithstanding, Mallo et al. (2019) demonstrated good correlations among different morphometric characteristics of the living shallow-water red coral, proposing some equations to relate them.
The main objectives of this study, to obtain size, age and growth rate data of this sub-fossil coral population, have shown that the Sciacca colonies existed for millennia and preserve the structure of the organic matrix, with evidence of annual discontinuities, allowing estimation of colony age. From the recorded basal diameters, the morphometric parameters of colonies have been estimated according to Mallo et al. (2019).

Considering the 18,000 tons of raw material collected and an estimated average weight of about $8 \mathrm{~g}$ per colony, it is very likely that about 2.25 billion colonies grew over a period of 8300 years on the Sciacca banks. Over this range of time, the number of the red coral generations that followed one another can be estimated as about 220, presuming an average colony age of 33 years, with an average calcimass in place of 86 tons per generation. At a minimum density of 5 colonies $\mathrm{m}^{-2}$, a value already recorded in similar habitats and at similar depths (Table 1), it is speculated that the surface of the rocky flanks of the valley over which the red coral populations thrived over the millennia, would have been less than $2 \mathrm{~km}^{2}$. This surface, compatible with that of the flank of the Graham Bank facing the Sciacca deposits, justifies the harvested quantities and depicts a realistic scenario.

The formation of these large coral deposits still leaves numerous open questions. Very likely, they are not related to unusual high productivity in this area, but to an interaction of oceanographic processes and geophysical phenomena that have affected the Sicily Channel in the last 10,000 years. Previously, Canestrini (1883) charged by the Italian Government to conduct the first survey of the Sciacca banks, suggested that earthquakes and deposition of volcanic ash linked to the eruption of Ferdinandea Island in the nineteenth century, resulted in the death and subsequent burial of these red coral colonies. However, a single volcanic phenomenon, although intense, could not explain the accumulation of such a large quantity of coral. Mazzarelli (1915), building on Canestrini's opinion (1883), suggested that periodic earthquakes, storms and strong sea currents could have gradually accumulated the deposits, an opinion later supported by Di Geronimo et al. (1993). The occurrence of numerous intact bases, commonly preserving parts of the original substrate, strongly support this hypothesis.
Table 1 Morphometric data of the Sciacca sub-fossil red corals obtained by the Ascione, De Simone and Rajola factories in Torre del Greco (Naples)

\begin{tabular}{lllll}
\hline & Total & Ascione & De Simone & Rajola \\
\hline Measured colonies $(\mathrm{N})$ & 125 & 11 & 14 & 100 \\
Av. basal diameter \pm SE $(\mathrm{mm})$ & $9.85 \pm 0.44$ & $9.8 \pm 0.65$ & $18.87 \pm 1.39$ & $8.74 \pm 0.29$ \\
Av. colony height \pm SE $(\mathrm{cm})$ & $8.0 \pm 0.39$ & $7.9 \pm 0.57$ & $15.8 \pm 1.2$ & $5.9 \pm 0.26$ \\
Av. colony weight \pm SE $(\mathrm{g})$ & $12.3 \pm 0.80$ & $12.1 \pm 1.19$ & $28.5 \pm 2.52$ & $8.0 \pm 0.54$ \\
\hline
\end{tabular}

The data relative to colony heights and weights were interpolated using the equations proposed by Mallo et al. (2019) for the Mediterranean red coral populations 
Table 2 Estimation of the growth rate by the organic matrix staining method (Marschal et al. 2004) and the radiocarbon age on ten selected samples of the Sciacca coral

\begin{tabular}{lllll}
\hline Specimens & Basal diameter $(\mathrm{mm})$ & $\begin{array}{l}\text { Rings }(\mathrm{N}) \\
\text { Age }(\text { years })\end{array}$ & $\begin{array}{l}\text { Annual growth rate } \\
(\mathrm{mm} / \text { years })\end{array}$ & $\begin{array}{l}\text { Calibrated } \\
\text { radiocarbon ages } \\
\left.(\text { YBP })^{*}\right)\end{array}$ \\
\hline 1A & 12 & 35 & 0.34 & $41 \pm 40$ \\
1B & 12.5 & 37 & 0.34 & $8334 \pm 44$ \\
2A & 11.5 & 34 & 0.34 & \\
2B & 11.5 & 31 & 0.37 & $3881 \pm 64$ \\
3A & 12.5 & 43 & 0.29 & \\
3B & 13 & 39 & 0.33 & $3302 \pm 58$ \\
4A & 12 & 38 & 0.31 & \\
4B & 10 & 36 & 0.28 & $2852 \pm 64$ \\
5A & 11.5 & 35 & 0.33 & $3027 \pm 72$ \\
5B & 13 & 33 & 0.39 & \\
6A & 8 & 31 & 0.26 & $3073 \pm 70$ \\
6B & 9 & 32 & 0.28 & \\
7A & 9 & 32 & 0.28 & \\
7B & 9.5 & 33 & 0.29 & $3127 \pm 68$ \\
8A & 8 & 31 & 0.26 & \\
8B & 8 & 30 & 0.27 & \\
9A & 9 & 30 & 0.30 & \\
9B & 9.5 & 29 & 0.33 & \\
10A & 7 & 30 & 0.23 & \\
10B & 8 & 32 & $0.3 \pm 0.0$ & \\
Average & $10.2 \pm 0.4$ & $33.5 \pm 0.8$ & & \\
\hline
\end{tabular}

Uncertainties correspond to one standard deviation confidence level (68.2\% probability)

${ }^{(*)} \mathrm{YBP}=$ Years before $1950 \mathrm{CE}$
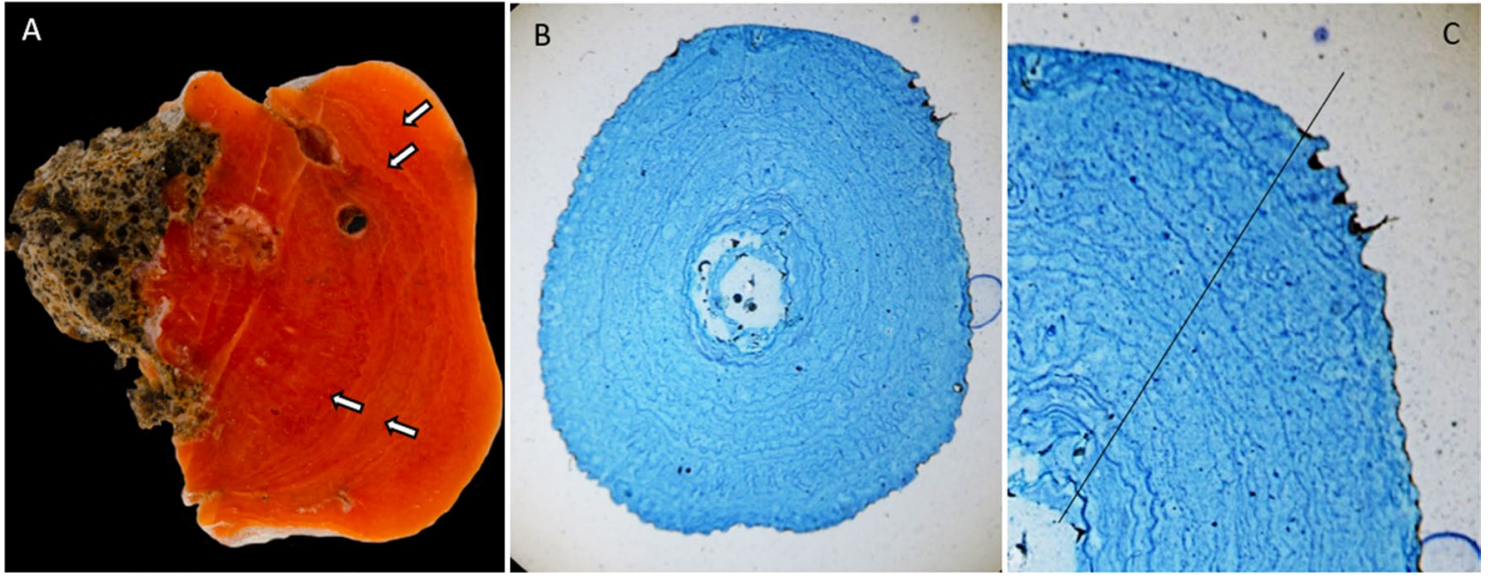

Fig. 5 Section of a colony base showing the extremely dense arrangement of the calcite crystals (a) and some of the annual growth rings (arrows). Section of a decalcified base of a red coral sub-fossil colony

Conversely, catastrophic tsunamis like the one that hit the eastern Mediterranean coast in the early Holocene (Pareschi et al. 2006), although proposed by Rajola (2012), has been excluded as a possible explanation, since it would likely have only impacted shallow-water environments. stained with Toluidine blue (b) and showing the annual discontinuity markers counted along a transect from the centre to the periphery (c)

The presence in the analysed samples (Table 2) of a large number of colonies dated between 2700 and 3900 YBP, could suggest that these populations were affected by the enormous explosive eruption of Thera that occurred in the late Holocene (about 3600 YBP) (Manning et al. 2014). The effects of this event could have reached the Sicily Channel 
Table 3 Morphometric parameters of deep red coral population in the Western Mediterranean and Atlantic Ocean

\begin{tabular}{|c|c|c|c|c|c|c|c|}
\hline & Sardinia (NW) & Sardinia (SW) & Sardinia (SE) & $\begin{array}{l}\text { Tuscany } \\
\text { Archi- } \\
\text { pelago }\end{array}$ & Costa Brava & Costa Brava & Portuguese Coast \\
\hline References & 1 & 2 & 2 & 3 & 4 & 5 & 6 \\
\hline Depth (m) & $80-130$ & $80-85$ & $88-115$ & $50-130$ & $70-90$ & $60-250$ & $80-100$ \\
\hline Density $\left(\mathrm{n} / \mathrm{m}^{2}\right)$ & $5.3 \pm 3$ & $12.8 \pm 16.1$ & $54.1 \pm 32.3$ & $1-100$ & - & $\begin{array}{l}42 \pm 41 \\
45 \pm 65\end{array}$ & - \\
\hline Av. age (years) & $\sim 30$ & 25.4 & 19.8 & 27.8 & - & - & $6.7-140.5$ \\
\hline Av. basal diameter (mm) & 10.7 & $7.9 \pm 4.9$ & 6.8 & 6.65 & 13.7 & $\begin{array}{l}8.3 \pm 3.6 \\
6.4 \pm 3.7 \\
5.5 \pm 2.0\end{array}$ & $10.6 \pm 5.18$ \\
\hline Av, growth rate (mm/year) & 0.35 & 0.32 & 0.35 & 0.26 & - & - & 0.23 \\
\hline Av. colony height $(\mathrm{cm})$ & 16.62 & $6.9 \pm 4.05$ & 6 & 8.92 & 118.6 & $\begin{array}{l}5.3 \pm 2.5 \\
5.5 \pm 2.7 \\
4.8 \pm 1.5\end{array}$ & - \\
\hline Av. colony weight (g) & 46.44 & - & - & - & 49.3 & - & - \\
\hline
\end{tabular}

1, Follesa et al (2013); 2, Cau et al (2015); 3, Priori et al (2013); 4, Garcia-Rodriguez and Massò (1986); 5, Rossi et al (2008); 6, Boavida et al. (2016)

through the Levantine Intermediate Water (LIW) (Font 1987), transporting an extraordinarily high amount of fine sediments. The information gap between 8300 and 3900 YPB and 2700 and 50 YPB remains hard to explain and could reflect the low number of analysed samples.

Through the Holocene to the present-day, recurrent submarine eruptions, like that of Ferdinandea Island, associated with small earthquakes, may have triggered periodic collapse of the friable pyroclastic steep flanks of the volcanoes on which the red coral lived (Lodolo et al. 2017; Fedorik et al. 2018). Furthermore, the burial conditions (Capaccioni et al. 2011) that followed these phenomena prevented the dissolution of the carbonate skeletons due to the activity of boring organisms. This is demonstrated by the scarcity of erosion marks on the examined fragments.

The morphometric analysis of the Sciacca specimens suggests populations composed of colonies with a basal diameter comparable with those present today at a similar depth (Table 3; Fig. 4). Also, the annual growth rate (about $0.3 \mathrm{~mm} /$ year) and the estimated population age (about 33.5 years) are in line with those found for deepdwelling living red coral populations (Table 1), suggesting that the structure and dynamics of red coral colonies have not changed in 8000 years. This conclusion is somewhat surprising, considering that the populations of the Sciacca bank have not been subjected to any fishing impact, one of the principal stressors driving the current demographic structures of the western Mediterranean populations (Tsounis et al. 2010; Bavestrello et al. 2014; Cattaneo-Vietti et al. 2016). Thus, the sub-fossil Sciacca populations can be considered pristine but with the characteristics of the actual disturbed deep-dwelling red coral populations (Table 1). This surprising similarity between ancient and recent populations can be explained by the fact that the first were fatally subjected to recurrent catastrophic phenomena, limiting their growth, and maintaining them in a persistent state of earlystage recovery (grass-like), structurally similar to the current over-exploited ones (Tsounis et al. 2006, 2010). These events may periodically zero entire populations, preventing them from reaching larger sizes (forest-like), as typical of colonies growing under stable conditions (Bavestrello et al. 2015).

Obviously, it is necessary to take also into consideration the idea that our data could be biased by the selection operated by the coral factories on the large colonies that were already being used in manufacture of jewelry. Nevertheless, numerous interviews with the owners did not corroborate this hypothesis. The explanation of the Sciacca banks formation is still speculative: the causes could be very different, but the consequences were similar.

Acknowledgements The authors wish to thank warmly the Ascione, De Simone, and Rajola factories from Torre del Greco for giving them the opportunity to study the Sciacca samples and Rocco de Marco for the map production.

Open Access This article is licensed under a Creative Commons Attribution 4.0 International License, which permits use, sharing, adaptation, distribution and reproduction in any medium or format, as long as you give appropriate credit to the original author(s) and the source, provide a link to the Creative Commons licence, and indicate if changes were made. The images or other third party material in this article are included in the article's Creative Commons licence, unless indicated otherwise in a credit line to the material. If material is not included in the article's Creative Commons licence and your intended use is not permitted by statutory regulation or exceeds the permitted use, you will need to obtain permission directly from the copyright holder. To view a copy of this licence, visit http://creativecommons.org/licenses/by/4.0/. 


\section{References}

Bavestrello G, Bo M, Canese S, Sandulli R, Cattaneo-Vietti R (2014) The red coral populations of the gulfs of Naples and Salerno: human impact and deep mass mortalities. Italian J Zool 81(4):552-563

Bavestrello G, Bo M, Bertolino M, Betti F, Cattaneo-Vietti R (2015) Long-term comparison of structure and dynamics of the red coral metapopulation of the Portofino Promontory (Ligurian Sea): a case-study for a Marine Protected Area in the Mediterranean Sea. Mar Ecol 36(4):1354-1363

Bramanti L, Vielmini I, Rossi S, Tsounis G, Iannelli M, Cattaneo-Vietti R, Priori C, Santangelo G (2014) Demographic parameters of two populations of red coral (Corallium rubrum L. 1758) in the NorthWestern Mediterranean. Mar Biol 161:1015-1026

Calcagnile L, Quarta G, D'Elia M (2005) High resolution acceleratorbased mass spectrometry: precision, accuracy and background. Appl Radiat Isotopes 62(4):623-629

Calcagnile L, Maruccio L, Scrimieri L, de Side D, Braione E, D'Elia M, Quarta G (2019) Development and application of facilities at the Centre for Applied Physics, Dating and Diagnostics (CEDAD) at the University of Salento during the last 15 years. Nuclear Instr Methods Phys Res Sect B Beam Interact Mater Atoms 456:252-256

Canestrini G, Canestrini R (1883) Il corallo. Annali Industria e Commercio (1882). Ministero Agricoltura, Industria, Commercio, Rome

Capaccioni B, Vaselli O, Tassi F, Santo AP, Huertas AD (2011) Hydrogeochemistry of the thermal waters from the Sciacca Geothermal Field (Sicily, southern Italy). J Hydrol 396(3):292-301

Cattaneo-Vietti R, Bavestrello G (2010) Sustainable use and conservation of precious corals in the Mediterranean. In: Iwasaki N (ed) Biohistory of precious corals. Tokai University Press, Tokai, pp $1-364$

Cattaneo-Vietti R, Bo M, Cannas R, Al C, Follesa C, Meliadò E, Russo GF, Sandulli R, Santangelo G, Bavestrello G (2016) An Italian overexploited treasure: past and present distribution and exploitation of the precious red coral Corallium rubrum (L., 1758) (Cnidaria, Anthozoa). Italian J Zool 83(4):443-455

Cattaneo-Vietti R, Bavestrello G, Bo M, Canese S, Vigo A, Andaloro F (2017) Illegal ingegno fishery and conservation of deep red coral banks in the Sicily Channel. Aquat Conserv Mar Freshw Ecosyst 27(3):1-13

Cau A, Cannas R, Sacco F, Follesa M.C (2013) Adaptive management plan for red coral (Corallium rubrum) in the GFCM competence area. University of Cagliari, p 50

Cau A, Paliaga EM, Cannas R, Deiana G, Follesa MC, Sacco F, Todde $S$, Orrù PE (2015) Preliminary data on habitat characterisation relevance for red coral conservation and management Italian. J Geosci 134(1):60-68

Cau A, Bramanti L, Cannas R, Follesa MC, Angiolillo M, Canese S, Guizien K (2016) Habitat constraints and self-thinning shape Mediterranean red coral deep population structure: implications for conservation practice. Sci Rep 6:23322

Coltelli M, Cavallaro D, D’Anna G, D'Alessandro A, Grassa F, Mangano $G$, Patanè D, Gresta $S$ (2016) Exploring the submarine Graham Bank in the Sicily channel. Ann Geophys 59(2):0208

Costantini F, Taviani M, Remia A, Pintus E, Schembri PJ, Abbiati M (2010) Deep-water Corallium rubrum (L., 1758) from the Mediterranean Sea: preliminary genetic characterisation. Mar Ecol 31(2):261-269

D’Elia M, Calcagnile L, Quarta G, Rizzo A, Sanapo C, Laudisa M, Toma U, Rizzo A (2004) Sample preparation and blank values at the AMS radiocarbon facility of the University of Lecce. Nucl Instr Methods Phys Res B 223-224:278-283
Di Stefano E, Incarbona A (2004) High-resolution palaeoenvironmental reconstruction of ODP Hole 963D (Sicily Channel) during the last deglaciation based on calcareous nannofossils. Mar Micropaleontol 52:241-254

Di Geronimo I, Rosso A, Sanfilippo R (1993) I banchi fossiliferi di Corallium rubrum al largo di Sciacca (Canale di Sicilia) In: Cicogna F and Cattaneo-Vietti R (eds), Il corallo rosso in Mediterraneo: arte, storia e scienza, pp 75-107

Fedorik J, Toscani G, Lodolo E, Civile D, Bonini L, Seno S (2018) Structural analysis and Miocene-to-Present tectonic evolution of a lithospheric-scale, transcurrent lineament: The Sciacca Fault (Sicilian Channel, Central Mediterranean Sea). Tectonophysics 722:342-355

Follesa MC, Cannas R, Cau A, Pedoni C, Pesci P, Cau A (2013) Deep-water red coral from the island of Sardinia (north-western Mediterranean): a local example of sustainable management. Mar Freshw Res 64(8):706-715

Font J (1987) The path of the Levantine intermediate water to the Alboran Sea Deep Sea. Res Part A Oceanogr Res Pap 34(10):1745-1755

Garcia-Rodriguez M, Masso' C (1986) Algunas bases para la determinacion directa de la edad del coral rojo (Corallium rubrum (L.) del Mediterraneo Boletin del Instituto. Espanol de Oceanografia 3(4):75-82

Knittweis L, Aguilar R, Alvarez H, Borg JA, Evans J, Garcia S, Schembri PJ (2016) New depth record of the precious red coral Corallium rubrum for the Mediterranean Rapports et Procés-Verbaux des Reunions Commission International pour l'Exploration Scientifique de la Mer Méditérranée Monaco, p 467

Liverino B (1998) Il corallo dalle origini ai nostri giorni Arte Grafica Ed, Napoli, pp 1-276

Lodolo E, Sanfilippo R, Rajola G, Canese S, Andaloro F, Montagna P, Rosso A, Macaluso D, Di Geronimo I, Caffau M (2017) The red coral deposits of the Graham Bank area: constraints on the Holocene volcanic activity of the Sicilian Channel. Geo Res J 13:126-133

Mallo M, Ziveri P, Reyes-García V, Rossi S (2019) Historical record of Corallium rubrum and its changing carbon sequestration capacity: a meta-analysis from the North-Western Mediterranean. PLoS ONE 14(12):e0223802

Manning SW, Höflmayer F, Moeller N, Dee MW, Ramsey CB, Fleitmann D et al (2014) Dating the Thera (Santorini) eruption: archaeological and scientific evidence supporting a high chronology. Antiquity 88(342):1164-1179

Marschal C, Garrabou J, Harmelin J-G, Pichon M (2004) A new method for measuring growth and age in the precious red coral Corallium rubrum. Coral Reefs 23:423-432

Mazzarelli G (1915) Banchi di corallo esplorati dalla R Nave "Volta" nell'estate del 1913 Annali dell'Industria Ministero dell'Agricoltura, Industria e Commercio Rome, pp 1-173

Neviani A (1935) Il corallo rosso fossile, saggio bibliografico-storico. Bollettino della Soc Geol Ital 54:51-66

Otero M, Numa C, Bo M, Orejas C, Garrabou J, Cerrano C, Kružic' P, Antoniadou C, Aguilar R, Linares C, Brossard J, Ocaña O, Kipson S, Terrón A, Kersting D, Goffredo S, Maldonado M, Caroselli E, Casado P, Garcia S, Bavestrello G, Cattaneo-Vietti R, Ozalp B (2016) Overview of the conservation status of Mediterranean Anthozoa IUCN Malaga Spain, pp 1-73

Pareschi MT, Boschi E, Favalli M (2006) Lost tsunami. Geophys Res Lett 33:22

Priori C, Mastascusa V, Erra F, Angiolillo M, Canese S, Santangelo G (2013) Demography of deep-dwelling red coral populations: age and reproductive structure of a highly valued marine species Estuarine, coastal and Shelf. Science 118:43-49 
Rajola G (2012) Mistero Sciacca Storia di un corallo di altri tempi. Edizioni Scientifiche e Artistiche Torre del Greco. ISBN 9788895430355. p 264

Rasband WS (1997) ImageJ. US National Institutes of Health, Bethesda, MD

Reimer P, McCormac F (2002) Marine Radiocarbon reservoir corrections for the Mediterranean and Aegean Seas. Radiocarbon 44:159-166

Reimer P, Bard E, Bayliss A, Beck JW, Blackwell PG, Bronk Ramsey C, Buck CE, Cheng H, Edwards RL, Friedrich M, Grootes PM, Guilderson TP, Haflidason H, Hajdas I, Hatté C, Heaton TJ, Hoffmann DL, Hogg AG, Hughen KA, Kaiser KF, Kromer B, Manning SW, Niu M, Reimer RW, Richards DA, Scott EM, Southon JR, Staff RA, Turney CSM, van der Plicht J (2013) IntCal13 and Marine13 radiocarbon age calibration curves 0-50,000 Years cal BP. Radiocarbon 55:4

Rossi S, Tsounis G, Orejas C, Padrón T, Gili JM, Bramanti L, Teixidò N, Gutt J (2008) Survey of deep-dwelling red coral (Corallium rubrum) populations at Cap de Creus (NW Mediterranean). Mar Biol 154:533-545

Taviani M, Freiwald A, Beuck L, Angeletti L, Remia A, Vertino A, Dimech M, Schembri PJ (2010) The deepest known occurrence of the precious red coral Corallium rubrum (L. 1758) in the Mediterranean Sea. In: Bussoletti E, Cottingham D, Bruckner A, Roberts G, Sandulli R (eds) Proceedings of the International Workshop on Red Coral Science, Management, and Trade: Lessons from the Mediterranean NOAA Technical Memorandum CRCP-13 Silver Spring MD 87-93

Tsounis G, Rossi S, Gili J-M, Arntz W (2006) Population structure of an exploited benthic cnidarian: the case study of red coral (Corallium rubrum L.). Mar Biol 149:1059-1070

Tsounis G, Rossi S, Grigg R, Santangelo G, Bramanti L, Gili J-M (2010) The exploitation and conservation of precious corals. Oceanogr Mar Biol Annu Rev 48:161-212

Vertino A, Zibrowius H, Rocca M, Taviani M (2010) Fossil Corallidae in the Mediterranean Basin. In: Bussoletti E, Cottingham D, Bruckner A, Roberts G, Sandulli R (eds) Proceedings of the international workshop on red coral science, management, and trade: lessons from the mediterranean NOAA Technical Memorandum CRCP-13 Silver Spring MD, pp 94-98

Vielmini I, Bramanti L, Tsounis G, Rossi S, Gili J-M, Cattaneo-Vietti R, Santangelo G (2009) Determination of Corallium rubrum population age structure. In: Bussoletti E, Cottingham D, Bruckner A, Roberts G, Sandulli R (eds) Proceedings of the international workshop on red coral science, management, and trade: lessons from the mediterranean NOAA Technical Memorandum CRCP-13 Silver Spring MD, pp 179-182

Vielzeuf D, Garrabou J, Baronnet A, Grauby O, Marschal C (2008) Nano to macroscale biomineral architecture of red coral (Corallium rubrum). Am Mineral 93:1799-1815 